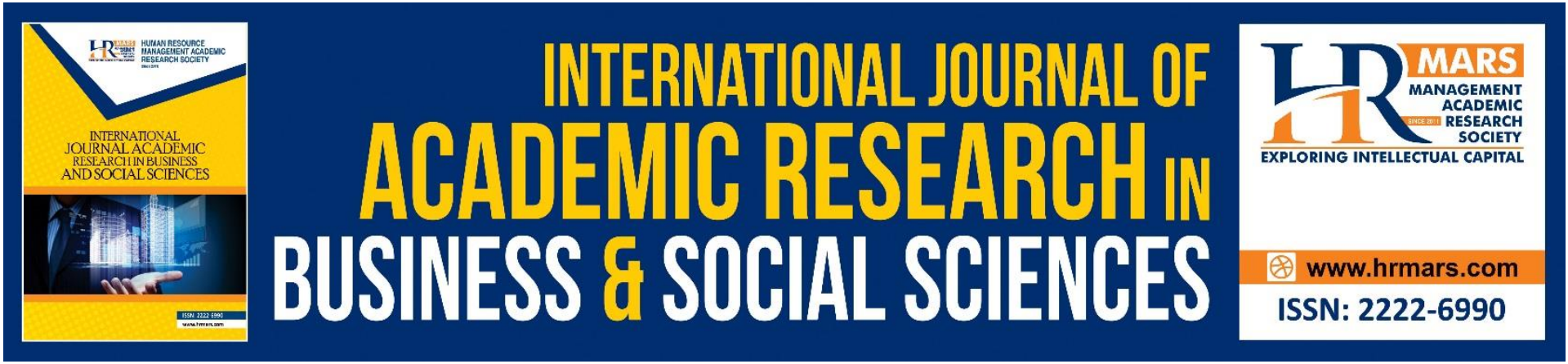

\title{
A 59 Years (1962-2021) Bibliometric Analysis of Organizational Support Research Articles
}

Brenda Ranee Francis, Rusli bin Ahmad \& Siti Mariam binti Abdullah

To Link this Article: http://dx.doi.org/10.6007/IJARBSS/v12-i1/12056 DOI:10.6007/IJARBSS/v12-i1/12056

Received: 16 November 2021, Revised: 21 December 2021, Accepted: 05 January 2022

Published Online: 26 January 2022

In-Text Citation: (Francis et al., 2022)

To Cite this Article: Francis, B. R., Ahmad, R. bin, \& Abdullah, S. M. binti. (2022). A 59 Years (1962-2021) Bibliometric Analysis of Organizational Support Research Articles. International Journal of Academic Research in Business and Social Sciences, 12(1), 1841-1863.

Copyright: (c) 2022 The Author(s)

Published by Human Resource Management Academic Research Society (www.hrmars.com)

This article is published under the Creative Commons Attribution (CC BY 4.0) license. Anyone may reproduce, distribute, translate and create derivative works of this article (for both commercial and non0-commercial purposes), subject to full attribution to the original publication and authors. The full terms of this license may be seen at: http://creativecommons.org/licences/by/4.0/legalcode

Vol. 12, No. 1, 2022, Pg. 1841- 1863

http://hrmars.com/index.php/pages/detail/IJARBSS

JOURNAL HOMEPAGE

Full Terms \& Conditions of access and use can be found at http://hrmars.com/index.php/pages/detail/publication-ethics 


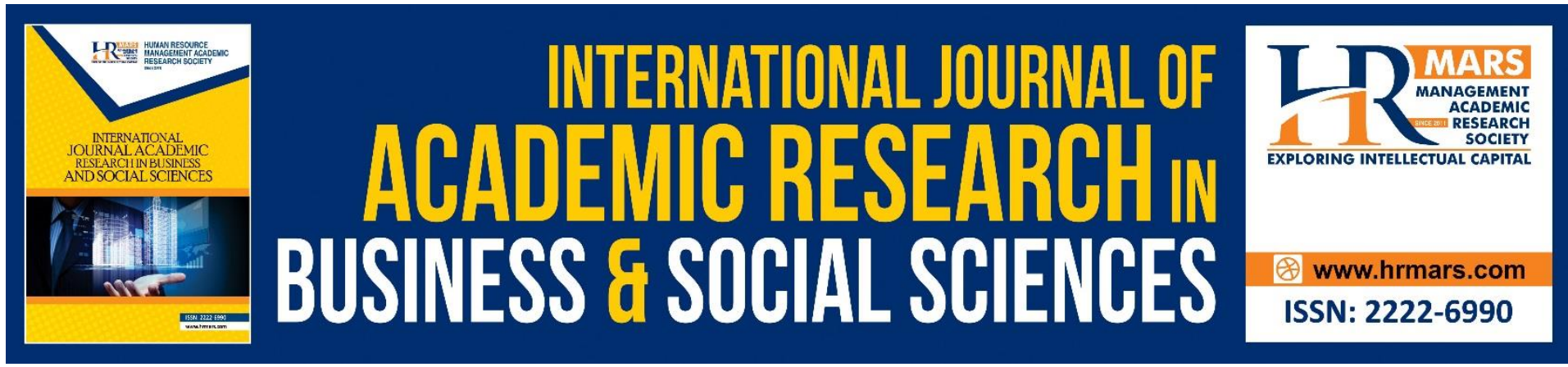

\title{
A 59 Years (1962-2021) Bibliometric Analysis of Organizational Support Research Articles
}

\section{Brenda Ranee Francis, Rusli bin Ahmad \& Siti Mariam binti Abdullah}

Faculty of Cognitive Sciences and Human Development, University Malaysia Sarawak, 94300

Kota Samarahan, Sarawak, Malaysia

\begin{abstract}
Organizational support is an administrative concern that emphasises well-being and appreciates employees' contributions. This study aims to determine the revolution of organizational support through published articles. This study employed 3 bibliometric analysis methods: descriptive analysis using Microsoft Excel, citation analysis using Publish or Perish software, and VOSviewer visualisation mapping. A total of 5527 articles within the last six decades (1962 - 2021) were retrieved from the Scopus database for analysis. A majority of the articles were published in the United States of America in the areas of Business, Management, and Accounting. Based on the review, the annual article publication trend has significantly increased each year. The University of Toronto was the most influential institution publishing organizational support articles, whereas, Robert Eisenberger is a wellknown author in this area. Also, the International Journal of Human Resource Management is an active source in this topic and Taylor \& Francis is a well-known thriving publisher. "Perceived Organizational Support" is the most popular article in this field. The information obtained from this study can be utilised by organizations, organizational policymakers, and researchers to identify future research gaps.
\end{abstract}

Keywords: Organizational Support, Perceived Organizational Support, Bibliometric Analysis, VOSviewer, Harzing's Publish or Perish

\section{Introduction}

The perceived organizational support felt by employees can positively impact the employees and the organization. Organizational support is an administrative concern on the well-being of the employees and appreciating their contribution to achieving organizational goals (Aselage \& Eisenberger, 2003; Baran et al., 2012; Eisenberger et al., 1986). Furthermore, the social responsibility perspective impacts the individuals more than the organizations due to the process of social exchange between employees and organizations (Eisenberger et al., 2001, 2020; Rockstuhl et al., 2020). Organizational support plays a vital role in encouraging and motivating employees to be committed to their jobs (Fazio et al., 2017). Studies on organizational support also revealed several antecedents that could lead to changes in employee attitudes, performance and well-being in the workplace (Baran et al., 2012; Eisenberger et al., 2020; Caesens et al., 2016; Eisenberger et al., 2020). 
Antecedents of organizational support including organizational justice, leader support, work environment conditions, and ethical human resource practices will incite more trust among employees (Arnéguy et al., 2020; Kurtessis et al., 2017). Consequently, employees will perform their obligations to the organization due to a positive reciprocal response norm (Arnéguy et al., 2020; Caesens et al., 2016). Previous scientific studies that explained the relationship between justice and organizational support also described that justice can influence the willingness of employees to change for the better (Arnéguy et al., 2020; Baran et al., 2012).

Previous studies also demonstrated that procedural fairness is positively related to organizational support (Arnéguy et al., 2018) because employees view procedural justice as the most influential type of justice and typically being the most considerable control in organizations (Arnéguy et al., 2020; Rockstuhl et al., 2020). Moreover, fairness principle procedures namely input, transparency, and honesty can help enhance the perceptions of high perceived organizational support among employees (Arnéguy et al., 2018; 2020). Employees under fair processes feel that the organization is more appreciative and concerned about their well-being (Arnéguy et al., 2020). However, negative reactions from the adoption of unfair processes can be detrimental to the organization. The adverse reactions include losing trust among employees, low job satisfaction, and the rupture of interpersonal relationships between employees and the organization. Hence, employees might resolve to quit their jobs due to the conflict and disharmony at the workplace (Caesens et al., 2019; Ekmekcioglu \& Aydogan, 2019; Zeffane \& Bani Melhem, 2017).

On the other hand, leader support is positively correlated with perceived organizational support (Eisenberger et al., 2020). Leaders with the support of the organization will positively emanate good leadership to fellow employees under their supervision. Good leadership can increase trust and performance through social exchange processes among employees and supervisors (Eisenberger et al., 2020). Employees tend to trust their leaders when their well-being is taken care of and conflicts at the workplace are reduced (Caesens et al., 2019; Gordon et al., 2019). Leaders who mentor, disseminate knowledge, appreciate and care for employee well-being will provoke positive emotions (Caesens et al., 2019; Hoak, 2021). In return, employees will show interest in the duties entrusted to them because diligent and committed employees will be rewarded based on their effort (Baran et al., 2012; Eisenberger et al., 2020; Nguyen et al., 2017; Caesens et al., 2016). Such rewards and awards are perceived as a sign of concern, appreciation, and respect towards the employees (Nguyen et al., 2017).

Organizational support felt by employees can also be assessed based on their attitudes, self-involvement in employment, employee performance, and commitment to the organization, especially in terms of affective commitment (Caesens et al., 2016; Eisenberger et al., 1986, 2020; Kim et al., 2016; Kurtessis et al., 2017b; Nazir et al., 2019; Rhoades et al., 2001; Shore \& Wayne, 1993). Affective commitment can be achieved when employees feel indebted and obligated to reciprocate organizational kindness (Aselage \& Eisenberger, 2003; Caesens et al., 2016; Eisenberger et al., 1986, 2001; Fazio et al., 2017). Employees reciprocate the organizational support through positive behaviours like improvement in work performance and workplace harmony. Contrarily, adverse effects can be observed based on the number of resignations and internal conflicts (Caesens et al., 2016, 2019; Eisenberger et 
al., 2020). Thus, a harmonious atmosphere, good treatment, respectful courtesy, and a conflict-free workplace can reduce stress among employees (Aldamman et al., 2019; Caesens et al., 2019; Eisenberger et al., 2020).

Based on the aforementioned review, this study aims to analyse the development of articles related to the study of organizational support from 1962 to 2021 . The research questions are as follows:

- What types of documents and sources are frequently used for article publication?

- What language is frequently used for article publication?

- What are the areas associated with organizational support studies?

- What is the development of the publication of organizational support articles each year?

- Which country has the highest publication of organizational support articles?

- Which institution has the most influential publication in the field of organizational support?

- Who is the most productive author in the publication of organizational support articles?

- Which source is most active in publishing articles?

- What is the status of the latest article citation metrics analysis?

- Which article is the most popular and has the highest citations?

- What are the most popular author keywords in publishing organizational support articles?

Articles retrieved through the Scopus database were analysed using the bibliometric method within the last six decades (1962- 2021). Exploration of extant organizational support articles using descriptive analysis, statistical calculations, and Vosviewer map visualisation highlighted publications of journal-sourced article-type documents. According to Pritchard (1969), bibliometrics is a mathematical and statistical exploratory technique of document publication involving communication media. In this study, 11 research questions serve as guides in exploring the research publications on organizational support.

The first section of this study described the introduction, objectives, and research questions. The second and third sections describe the literature review and research methodology, respectively. The fourth section illustrates the results and discusses the analysis in a descriptive form and the form of a Vosviewer visualization map. While section five, where the final section provides an overall conclusion, which also covers the limitations of the research and future research recommendations.

\section{Literature Review}

Organizational support theory explains employees' perceptions of corporate concern in appreciating employee contributions and caring for their well-being (Aselage \& Eisenberger, 2003). The theory also emphasises the importance of maintaining employee motivation as it is relevant to organizational goals and performance (Aselage \& Eisenberger, 2003). If employees and organizations work together in completing the activities together, they could receive mutual benefits.

Organizational support should be incorporated at a reasonable discretion to generate creativity towards innovation, produce positive emotions, and create employee well-being (Eisenberger et al., 2020; Nazir et al., 2019). Such organizational support could increase job satisfaction, belongingness to the organization, reduce stress and cognitive burden felt by 
employees (Andoh et al., 2021; Caesens et al., 2016; Côté et al., 2021; Eisenberger et al., 2020). According to the social exchange theory, workers should emphasise the norm of reciprocity by returning the favours and performing obligations that should be performed with commensurate rewards (Aselage \& Eisenberger, 2003; Eisenberger et al., 2001). As such, employees' positive emotions and performance are the results of the reciprocity norms of organizational support (Eisenberger et al., 2001). Thus, the resulting well-being of the employee will be based on the social exchange that helps shape the psychology of contracts between the employees and organizations (Aselage \& Eisenberger, 2003).

According to Eisenberger et al (2020), organizational support explains the relationship between organizations and employees that existed in various cultures relevant to organizational support in the workplace. Moreover, Eisenberger et al. (1986) also added that employees perceive the organization as a living entity that strives to achieve organizational goals. In conclusion, organizational support prioritises the strengthening of relationships between the employees and the organization to improve employee well-being while benefiting the organization (Baran et al., 2012; Kurtessis et al., 2017).

\section{Methodology}

The article search through the Scopus database was performed on January $4^{\text {th }}, 2022$. The Scopus database is the largest most indexed database with the highest data citation rate among other databases (Burnham, 2006). The publication searches focused on document type, source, language, field, year, country, institution, well-known author, most active sources, popular articles, and keywords. Document publication searches on journal article type documents focused on titles, abstracts, and keywords. While Scopus data search was based on inquiries such as TITLE-ABS-KEY ( ( "perceived organization support*" OR "perceived organizational support*" OR "organization support*" OR "organizational support*" OR "organisational support*" OR "perceived organisational support*" ) ) from 1962 to 2021.

A total of 7202 documents were obtained through document search results from the Scopus database. A total of 1675 document was removed and focused only on a total of 5527 journal-sourced articles. The list of journal articles was exported in comma-separated values (.csv) and research information systems (.ris). The (.csv) files were analysed using Microsoft Excel to obtain a descriptive analysis (Ahmi \& Mohamad, 2019). Meanwhile, the ris files were analysed using Harzing's Publish or Perish and VOSviewer software to visualize the study map (Van Eck \& Waltman, 2020; Wong, 2018). Figure 1 illustrates the Scopus database search based on the protocol guidelines. 

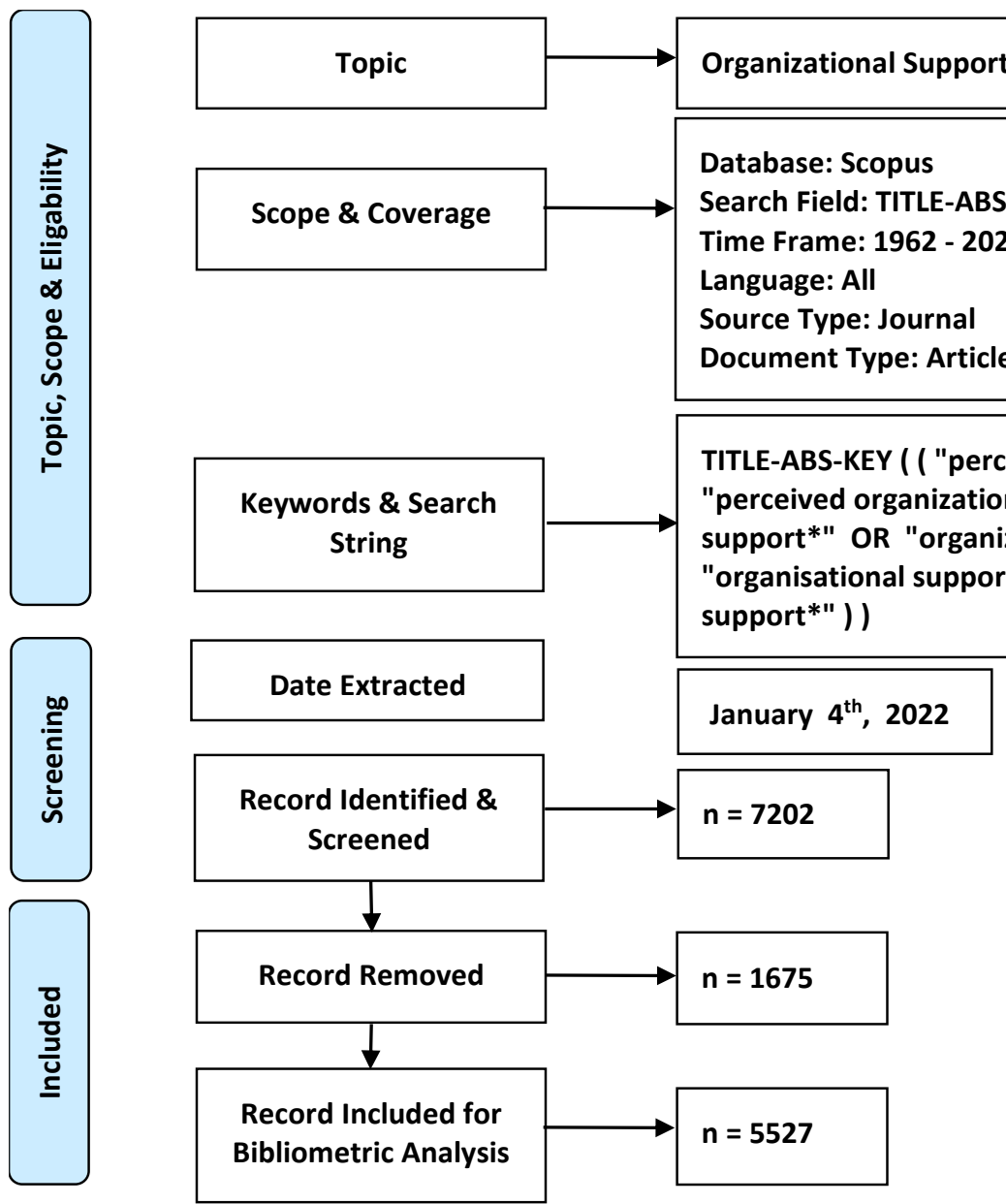

Figure 1. Flow diagram of the search strategy

[Source: Moher et al. (2009) and Zakaria et al. (2021)]

\section{Results and Discussion}

The findings are discussed in the form of descriptions and mapping visualisation. Each research question was answered and discussed as follows:-

- What types of documents and resources are frequently used for article publication?

The types of documents and sources in this study focused only on the journal-sourced articles. Based on the search results of the overall publication data, the article type document is the highest published document compared to other published papers. Therefore, this study only focused on documents in the form of journal articles. This study specifically focused on organizational support topics based on keywords, titles, and abstracts. Through Scopus database search, 5527 articles were retrieved to be used as the study data. Also, the inspection results indicated no papers were published twice.

\section{- What language is frequently used for article publication?}

According to Table 1, most of the organizational support articles were published in English $(n=5324,95.60 \%)$. The second most common language used in the publications was Spanish $(n=45,0.81 \%)$. Followed by French $(n=38,0.68 \%)$, German $(n=25,0.45 \%)$, and Portuguese $(n=23,0.41 \%)$. Meanwhile, the other languages used in the related publications were less than 20 articles each. Based on this observation, English is the leading language of choice for 
authors because it is an international language that is widely understood. Moreover, the use of English in article writing can increase the number of readers and number of citations which in turn escalate the $h$-index and g-index of the articles.

Table 1. Languages in which articles were published

\begin{tabular}{lll}
\hline Language & TP & \% \\
\hline English & 5324 & $95.60 \%$ \\
Spanish & 45 & $0.81 \%$ \\
French & 38 & $0.68 \%$ \\
German & 25 & $0.45 \%$ \\
Portuguese & 23 & $0.41 \%$ \\
Chinese & 20 & $0.36 \%$ \\
Russian & 18 & $0.32 \%$ \\
Italian & 13 & $0.23 \%$ \\
Japanese & 10 & $0.18 \%$ \\
Korean & 9 & $0.16 \%$ \\
Persian & 8 & $0.14 \%$ \\
Ukrainian & 8 & $0.14 \%$ \\
Turkish & 4 & $0.07 \%$ \\
Czech & 3 & $0.05 \%$ \\
Malay & 3 & \\
Croatian & 2 & $0.05 \%$ \\
Dutch & 2 & $0.04 \%$ \\
Slovenian & 2 & $0.04 \%$ \\
Swedish & 2 & $0.04 \%$ \\
Afrikaans & 1 & $0.04 \%$ \\
\hline
\end{tabular}

- What are the areas associated with organizational support studies?

Table 2 indicates that a majority of the organizational support topics were published in the field of Business, Management, and Accounting ( $n=2010,36.37 \%)$. Meanwhile, Social Sciences was the second-highest publication with 1654 articles $(29.93 \%)$, followed by the field of Medicine ( $n=1386,25.08 \%)$, Psychology ( $n=1036,18.74 \%)$, and Nursing ( $n=675,12.21 \%)$. The other fields contributed $37(0.67 \%)$ to $292(5.28 \%)$ articles. The number of articles published in the field of Earth and Planetary Sciences was the lowest with only 37 articles (0.67\%). Based on this observation, most organizational support topics were published in Business, Management, and Accounting, Social Sciences, Medicine, Psychology, and Nursing journals. The areas mentioned involve social relationships between human beings interacting within organizations involving economics and politics. Interactions between people were assessed based on behaviour, culture, well-being, and its effects on the current organizational situation. 
Table 2. Subject area

\begin{tabular}{lll}
\hline Subject Area & TP & \% \\
\hline Business, Management and Accounting & 2010 & $36.37 \%$ \\
Social Sciences & 1654 & $29.93 \%$ \\
Medicine & 1386 & $25.08 \%$ \\
Psychology & 1036 & $18.74 \%$ \\
Nursing & 675 & $12.21 \%$ \\
Economics, Econometrics and Finance & 292 & $5.28 \%$ \\
Engineering & 288 & $5.21 \%$ \\
Computer Science & 280 & $5.07 \%$ \\
Arts and Humanities & 275 & $4.98 \%$ \\
Decision Sciences & 251 & $4.54 \%$ \\
Environmental Science & 221 & $4.00 \%$ \\
Health Professions & 127 & $2.30 \%$ \\
Agricultural and Biological Sciences & 94 & $1.70 \%$ \\
Biochemistry, Genetics and Molecular Biology & 90 & $1.63 \%$ \\
Energy & 70 & $1.27 \%$ \\
Multidisciplinary & 60 & $1.09 \%$ \\
Mathematics & 48 & $0.87 \%$ \\
Neuroscience & 45 & $0.81 \%$ \\
Pharmacology, Toxicology and Pharmaceutics & 38 & $0.69 \%$ \\
Earth and Planetary Sciences & 37 & $0.67 \%$ \\
\hline
\end{tabular}

- What is the development of the publication of organizational support articles each year? The bibliometric analysis in Table 3 illustrates the publication of articles over the last 59 years (1962 to 2021). According to Figure 2, there is a significant increasing trend of publications each year. The lowest publication trend was recorded in the years 1962 and 1970 with only 1 article publication for each year, while the highest number of publications were reported in the year $2020(n=578)$. The highest number of citations were reported in the year 2010, with a total of 13007 citations. Meanwhile, the year 1970 recorded the lowest citation. Meanwhile, the highest average citation was 716.33 citations per article in the year 1986 . Moreover, articles published in the years 1986, 1997, 2002 and 2001 were highly cited because some of the articles were written by famous authors such as Eisenberger, Wayne, and Rhoades. 
Table 3. Year of publication

\begin{tabular}{|c|c|c|c|c|c|c|c|c|}
\hline Year & TP & $\%$ & NCP & TC & $\mathrm{C} / \mathrm{P}$ & $\mathrm{C} / \mathrm{CP}$ & $\mathbf{h}$ & $\mathbf{g}$ \\
\hline 2021 & 503 & $9.10 \%$ & 223 & 694 & 1.38 & 3.11 & 10 & 15 \\
\hline 2020 & 578 & $10.46 \%$ & 434 & 2527 & 4.37 & 5.82 & 19 & 30 \\
\hline 2019 & 480 & $8.68 \%$ & 406 & 3750 & 7.81 & 9.24 & 23 & 41 \\
\hline 2018 & 436 & $7.89 \%$ & 398 & 4829 & 11.08 & 12.13 & 30 & 44 \\
\hline 2017 & 374 & $6.77 \%$ & 334 & 5636 & 15.07 & 16.87 & 38 & 57 \\
\hline 2016 & 353 & $6.39 \%$ & 326 & 6900 & 19.55 & 21.17 & 40 & 64 \\
\hline 2015 & 336 & $6.08 \%$ & 304 & 5805 & 17.28 & 19.10 & 39 & 54 \\
\hline 2014 & 301 & $5.45 \%$ & 282 & 6628 & 22.02 & 23.50 & 43 & 62 \\
\hline 2013 & 277 & $5.01 \%$ & 257 & 9702 & 35.03 & 37.75 & 48 & 90 \\
\hline 2012 & 230 & $4.16 \%$ & 215 & 7439 & 32.34 & 34.60 & 44 & 78 \\
\hline 2011 & 185 & $3.35 \%$ & 178 & 6928 & 37.45 & 38.92 & 44 & 76 \\
\hline 2010 & 192 & $3.47 \%$ & 176 & 13007 & 67.74 & 73.90 & 51 & 112 \\
\hline 2009 & 180 & $3.26 \%$ & 176 & 8987 & 49.93 & 51.06 & 50 & 89 \\
\hline 2008 & 136 & $2.46 \%$ & 124 & 9950 & 73.16 & 80.24 & 45 & 99 \\
\hline 2007 & 127 & $2.30 \%$ & 122 & 7653 & 60.26 & 62.73 & 49 & 85 \\
\hline 2006 & 109 & $1.97 \%$ & 106 & 8476 & 77.76 & 79.96 & 42 & 91 \\
\hline 2005 & 63 & $1.14 \%$ & 59 & 2801 & 44.46 & 47.47 & 28 & 52 \\
\hline 2004 & 61 & $1.10 \%$ & 56 & 3242 & 53.15 & 57.89 & 27 & 56 \\
\hline 2003 & 66 & $1.19 \%$ & 63 & 4996 & 75.70 & 79.30 & 31 & 66 \\
\hline 2002 & 72 & $1.30 \%$ & 68 & 10166 & 141.19 & 149.50 & 36 & 72 \\
\hline 2001 & 66 & $1.19 \%$ & 65 & 9186 & 139.18 & 141.32 & 29 & 66 \\
\hline 2000 & 55 & $1.00 \%$ & 50 & 3645 & 66.27 & 72.90 & 25 & 55 \\
\hline 1999 & 44 & $0.80 \%$ & 39 & 4493 & 102.11 & 115.21 & 22 & 44 \\
\hline 1998 & 33 & $0.60 \%$ & 28 & 3542 & 107.33 & 126.50 & 17 & 13 \\
\hline 1997 & 34 & $0.62 \%$ & 30 & 5136 & 151.06 & 171.20 & 22 & 34 \\
\hline 1996 & 41 & $0.74 \%$ & 35 & 2587 & 63.10 & 73.91 & 17 & 41 \\
\hline 1995 & 36 & $0.65 \%$ & 29 & 4975 & 138.19 & 171.55 & 17 & 36 \\
\hline 1994 & 20 & $0.36 \%$ & 14 & 272 & 13.60 & 19.43 & 8 & 16 \\
\hline 1993 & 13 & $0.24 \%$ & 12 & 13 & 1.00 & 1.08 & 5 & 13 \\
\hline 1992 & 25 & $0.45 \%$ & 22 & 1070 & 42.80 & 48.64 & 15 & 25 \\
\hline 1991 & 12 & $0.22 \%$ & 8 & 977 & 81.42 & 122.13 & 7 & 12 \\
\hline 1990 & 14 & $0.25 \%$ & 13 & 1896 & 135.43 & 145.85 & 7 & 14 \\
\hline 1989 & 6 & $0.11 \%$ & 5 & 104 & 17.33 & 20.80 & 4 & 6 \\
\hline 1988 & 13 & $0.24 \%$ & 12 & 404 & 31.08 & 33.67 & 8 & 13 \\
\hline 1987 & 7 & $0.13 \%$ & 6 & 115 & 16.43 & 19.17 & 5 & 7 \\
\hline 1986 & 6 & $0.11 \%$ & 3 & 4298 & 716.33 & 1432.67 & 3 & 6 \\
\hline 1985 & 7 & $0.13 \%$ & 6 & 282 & 40.29 & 47.00 & 5 & 7 \\
\hline 1984 & 8 & $0.14 \%$ & 7 & 18 & 2.25 & 2.57 & 2 & 3 \\
\hline 1983 & 2 & $0.04 \%$ & 2 & 107 & 53.50 & 53.50 & 2 & 2 \\
\hline 1982 & 3 & $0.05 \%$ & 2 & 54 & 18.00 & 27.00 & 2 & 3 \\
\hline 1981 & 3 & $0.05 \%$ & 1 & 1 & 0.33 & 1.00 & 1 & 1 \\
\hline 1980 & 7 & $0.13 \%$ & 3 & 141 & 20.14 & 47.00 & 3 & 7 \\
\hline 1979 & 3 & $0.05 \%$ & 3 & 36 & 12.00 & 12.00 & 1 & 3 \\
\hline 1978 & 5 & $0.09 \%$ & 4 & 69 & 13.80 & 17.25 & 2 & 5 \\
\hline
\end{tabular}




$\begin{array}{lllllllll}1977 & 3 & 0.05 \% & 2 & 19 & 6.33 & 9.50 & 2 & 3 \\ 1970 & 1 & 0.02 \% & 0 & 0 & 0.00 & 0.00 & 0 & 0 \\ 1962 & 1 & 0.02 \% & 1 & 2 & 2.00 & 2.00 & 1 & 1\end{array}$

Notes: $\mathrm{TP}=$ total number of publications; $\mathrm{NCP}=$ number of cited publications; $\mathrm{TC}=$ total citations; $C / P=$ average citations per publication; $C / C P=$ average citations per cited publication; $h=h$-index; and $g=g$-index.

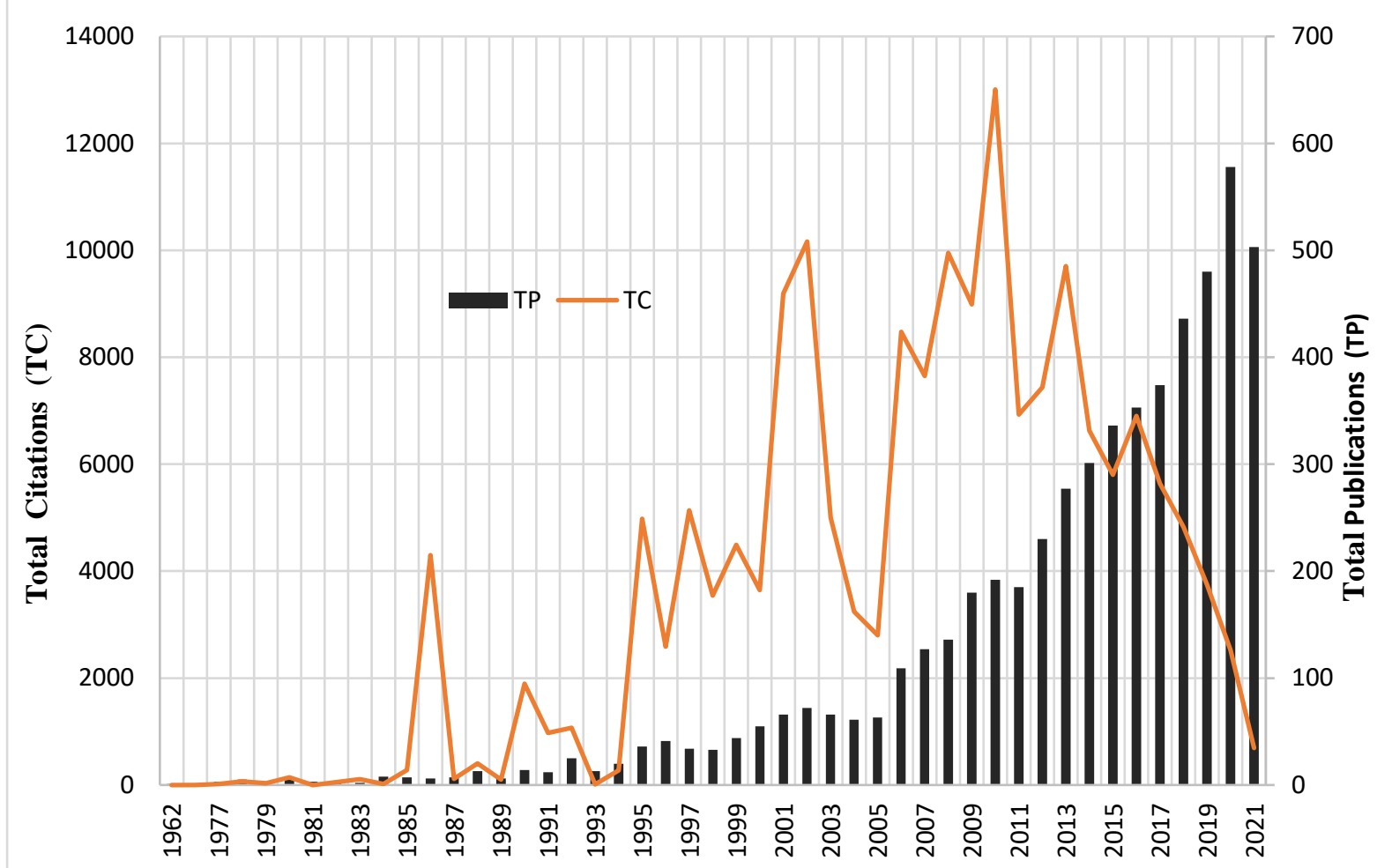

Years

Figure 2. Total publications and citations by year

- Which country has the highest publication of organizational support articles?

Table 4 and figure 3, summarises the top 20 most productive countries in publishing articles and the geographical distribution of the publication. The United States was the most productive country contributing to the publication of articles on organizational support. Followed by the United Kingdom ( $n=515,9.32 \%)$, Australia $(n=488,8.83 \%)$, Canada ( $n=419$, $7.58 \%)$, and China ( $n=316,5.72 \%)$. The remaining countries contributed between $3.42 \%$ to $1.43 \%$ of articles. Hong Kong published the least number of articles with only 79 articles in the past 59 years. On the other hand, the United States recorded the highest number of citations over 59 years (96374 citations), followed by Canada (18732 citations), the United Kingdom (14545 citations), and Australia (12338 citations). The country with the lowest citation was Iran (513 citations). The other countries cited between 870 to 5658 citations over 59 years. The highest average number of citations for an article over 59 years was 63.18 citations in Hong Kong. Whereas, Iran recorded the lowest number of citations, with an average of 6.26 citations per article. The United States recorded the highest $h$-index reading with an h-index of 138 and 1674 cited articles, whereas only 133 articles had 0 citations. The h-index for Hong Kong was 35, where at least 73 articles cited out of a total of 79 were published. 
The United States recorded an average annual citation of 53.33 compared to Hong Kong, which has the highest yearly citation average of 63.18 . Hong Kong only published 79 articles in the last 59 years. Nevertheless, Hong Kong scored the highest average citation rate since almost all articles that were published were cited, except for 6 articles with 00 citations. Contrarily, the country with the lowest citation was Iran and Malaysia with an average citation of 6.26 to 6.47. Compared to the number of publications over 59 years, the number of articles published in Malaysia was relatively higher compared to some other countries with low publications but higher citations. Meanwhile, some countries recorded a relatively high average annual citation despite publishing relatively fewer articles, such as Hong Kong, Belgium, and the Netherlands.

Table 4. Top 20 countries contributed to the publications

\begin{tabular}{lllllllll}
\hline Country & TP & \% & NCP & TC & C/P & C/CP & $\mathbf{h}$ & $\mathbf{g}$ \\
\hline United States & 1807 & $32.69 \%$ & 1674 & 96374 & 53.33 & 57.57 & 138 & 266 \\
\hline United Kingdom & 515 & $9.32 \%$ & 467 & 14545 & 28.24 & 31.15 & 61 & 104 \\
\hline Australia & 488 & $8.83 \%$ & 443 & 12338 & 25.28 & 27.85 & 56 & 92 \\
\hline Canada & 419 & $7.58 \%$ & 382 & 18732 & 44.71 & 49.04 & 60 & 127 \\
\hline China & 316 & $5.72 \%$ & 261 & 5615 & 17.77 & 21.51 & 38 & 63 \\
\hline South Korea & 189 & $3.42 \%$ & 158 & 4734 & 25.05 & 29.96 & 35 & 65 \\
\hline India & 181 & $3.27 \%$ & 124 & 2003 & 11.07 & 16.15 & 23 & 40 \\
\hline Malaysia & 161 & $2.91 \%$ & 117 & 1042 & 6.47 & 8.91 & 17 & 25 \\
\hline Germany & 157 & $2.84 \%$ & 141 & 4645 & 29.59 & 32.94 & 33 & 65 \\
\hline Netherlands & 145 & $2.62 \%$ & 137 & 5658 & 39.02 & 41.30 & 39 & 71 \\
\hline France & 121 & $2.19 \%$ & 109 & 2813 & 23.25 & 25.81 & 29 & 49 \\
\hline Taiwan & 120 & $2.17 \%$ & 114 & 3483 & 29.03 & 30.55 & 31 & 56 \\
\hline Spain & 119 & $2.15 \%$ & 105 & 1757 & 14.76 & 16.73 & 22 & 37 \\
\hline Italy & 103 & $1.86 \%$ & 94 & 2889 & 28.05 & 30.73 & 22 & 52 \\
\hline Sweden & 99 & $1.79 \%$ & 88 & 2003 & 20.23 & 22.76 & 24 & 42 \\
\hline Pakistan & 98 & $1.77 \%$ & 76 & 870 & 8.88 & 11.45 & 19 & 25 \\
\hline Belgium & 96 & $1.74 \%$ & 85 & 4352 & 45.33 & 51.20 & 27 & 65 \\
\hline South Africa & 89 & $1.61 \%$ & 76 & 1185 & 13.31 & 15.59 & 15 & 32 \\
\hline Iran & 82 & $1.48 \%$ & 52 & 513 & 6.26 & 9.87 & 14 & 20 \\
\hline Hong Kong & 79 & $1.43 \%$ & 73 & 4991 & 63.18 & 68.37 & 35 & 70 \\
\hline
\end{tabular}




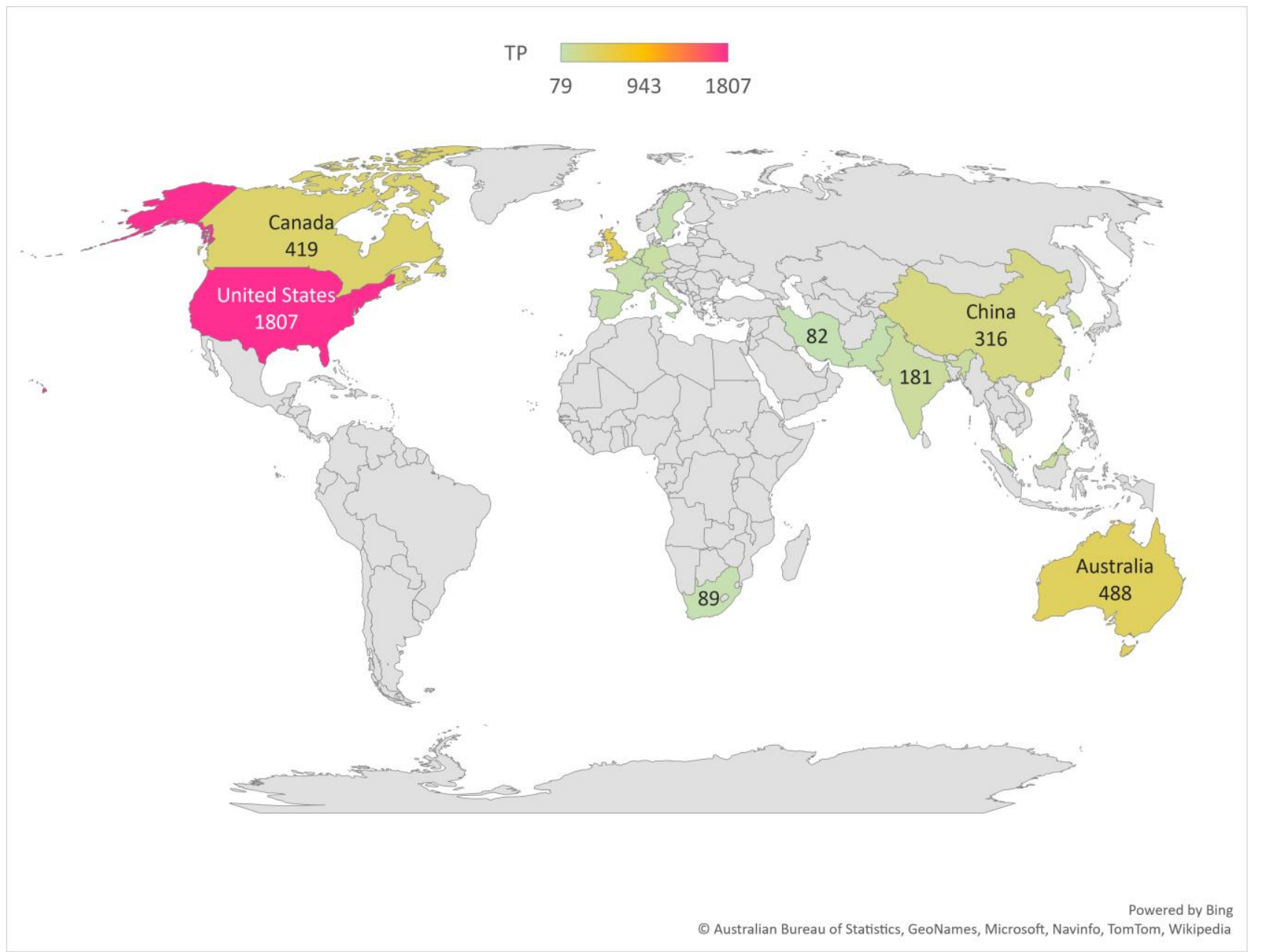

Figure 3. Geographical Distribution of Publication

- Which institution has the most influential publication in the field of organizational support?

Table 6, summarises the top 10 most influential institutions with a minimum publication of 36 articles. The highest contributing institution to the publication on organizational support was the University of Toronto, with 74 published articles. Followed by the University of Houston (TP=47), Monash University (TP=44) and Florida State University (TP=42). Meanwhile, other institutions published between 36 to 39 articles in 59 years.

7150

The University of Illinois at Chicago also recorded the highest article citations, with University of Toronto (TC=4162), followed by Michigan State University ( $T C=2638$ ) and the University of Houston (TC=2631). Moreover, the University of Illinois, Chicago recorded the highest average citation per publication in 59 years $(C / P=198.6)$, succeeded by the Michigan State University $(C / P=71.3)$ and Florida State University $(C / P=61.6)$. Meanwhile, Monash University had the lowest number of average citation per publications $(C / P=23.1)$. On the other hand, the University of Toronto published the most number of articles compared to the University of Illinois (Table 6). However, the University of Illinois in Chicago scored the highest average citation per issue of 198.6 citations compared to the University of Toronto. 
Table 6. Most Influential Institutions with a Minimum of 36 Publications

\begin{tabular}{lllllllll}
\hline Institution & TP & Country & NCP & TC & C/P & C/CP & h & g \\
\hline University of Toronto & 74 & Canada & 68 & 4162 & 56.2 & 61.2 & 24 & 64 \\
\hline University of Houston & 47 & United States & 46 & 2631 & 56.0 & 57.2 & 24 & 47 \\
\hline Monash University & 44 & Australia & 37 & 1016 & 23.1 & 27.5 & 18 & 31 \\
\hline Florida State University & 42 & United States & 42 & 2586 & 61.6 & 61.6 & 25 & 42 \\
\hline La Trobe University & 39 & Australia & 35 & 912 & 23.4 & 26.1 & 15 & 30 \\
\hline University of Melbourne & 39 & Australia & 37 & 1303 & 33.4 & 35.2 & 16 & 36 \\
\hline UnSW Sydney & 39 & Australia & 37 & 928 & 23.8 & 25.1 & 13 & 30 \\
\hline Pennsylvania State University & 38 & United States & 36 & 1525 & 40.1 & 42.4 & 19 & 38 \\
\hline Michigan State University & 37 & United States & 34 & 2638 & 71.3 & 77.6 & 18 & 37 \\
\hline University of Illinois at Chicago & 36 & United States & 36 & 7150 & 198.6 & 198.6 & 25 & 36 \\
\hline
\end{tabular}

- Who is the most Productive author in the Publication of Organizational Support Articles?

Table 7 lists the top 10 most productive authors in the publication of articles related to organizational support. Robert Eisenberger was the most prolific author having published a total of 29 articles from the University of Houston, United States. Florence Stinglhamber (24) and Yvonne Brunetto (18) were the two other most productive authors. Furthermore, Eisenberger's publications also scored the highest TC of 16314 citations, with an average citation per article publication of 562.55. He also recorded the highest g-index and h-index values (23 h-index and 29 g-index). Meanwhile, authors with the lowest number of article publications were Philippe $\mathrm{H}$. Colombat with 12 articles. Whereas the lowest cited author was Ishfaq Ahmed from the University of Punjab with only 174 citations and an average citations per article publication of 10.88 .

Table 7. Top 10 most productive authors

\begin{tabular}{|c|c|c|c|c|c|c|c|c|c|}
\hline Author Name & Affiliation & Country & TP & NCP & TC & $C / P$ & $\mathrm{C} / \mathrm{CP}$ & $\mathbf{h}$ & g \\
\hline \multirow{2}{*}{$\begin{array}{l}\text { Eisenberger, } \\
\text { R. }\end{array}$} & University & United & & & 1631 & 562.5 & & & \\
\hline & of Houston & States & 29 & 29 & 4 & 5 & 562.55 & 23 & 29 \\
\hline \multirow{5}{*}{$\begin{array}{l}\text { Stinglhamber, } \\
\text { F. }\end{array}$} & Université & & & & & & & & \\
\hline & Catholique & & & & & & & & \\
\hline & de Louvain & Belgium & 24 & 23 & 2142 & 89.25 & 93.13 & 13 & 24 \\
\hline & Southern & & & & & & & & \\
\hline & Cross & Australia & & & & & & & \\
\hline \multirow[t]{3}{*}{ Brunetto, Y. } & University & & 18 & 18 & 422 & 23.44 & 23.44 & 11 & 18 \\
\hline & University & & & & & & & & \\
\hline & of the & & & & & & & & \\
\hline \multirow[t]{4}{*}{ Ahmed, I. } & Punjab & Pakistan & 16 & 14 & 174 & 10.88 & 12.43 & 8 & 13 \\
\hline & Qualité de & & & & & & & & \\
\hline & Vie et & & & & & & & & \\
\hline & Santé & & & & & & & & \\
\hline \multirow{3}{*}{$\begin{array}{l}\text { Fouquereau, } \\
\text { E. }\end{array}$} & Psychologi & & & & & & & & \\
\hline & que & France & 16 & 16 & 500 & 31.25 & 31.25 & 11 & 16 \\
\hline & Qualité de & & & & & & & & \\
\hline Gillet, N. & Vie et & France & 15 & 15 & 497 & 33.13 & 33.13 & 11 & 15 \\
\hline
\end{tabular}




\begin{tabular}{|c|c|c|c|c|c|c|c|c|c|}
\hline & $\begin{array}{l}\text { Santé Psy- } \\
\text { chologique }\end{array}$ & & & & & & & & \\
\hline & HEC & & & & & & & & \\
\hline & MontréalH & & & & & & & & \\
\hline Vandenbergh & $\mathrm{EC}$ & & & & & 146.3 & & & \\
\hline \multirow[t]{3}{*}{ e, $\mathrm{C}$. } & Montréal & Canada & 15 & 14 & 2195 & 3 & 156.79 & 11 & 15 \\
\hline & Université & & & & & & & & \\
\hline & Catholique & & & & & & & & \\
\hline \multirow[t]{4}{*}{ Caesens, G. } & de Louvain & Belgium & 14 & 13 & 452 & 32.29 & 34.77 & 9 & 14 \\
\hline & The & & & & & & & & \\
\hline & University & & & & & & & & \\
\hline & of North & United & & & & 113.3 & & & \\
\hline Shanock, L.R. & Carolina & States & 13 & 12 & 1474 & 8 & 122.83 & 8 & 13 \\
\hline Colombat,P & $\begin{array}{l}\text { Université } \\
\text { de Tours }\end{array}$ & France & 12 & 12 & 335 & 27.92 & 27.92 & 7 & 12 \\
\hline
\end{tabular}

\section{- Which source is most active in publishing articles?}

According to Table 9, the most active source among the 10 sources was the International Journal of Human Resource Management with 74 successful article publications. Succeeded by International Journal of Environmental Research and Public Health (52), Journal of Applied Psychology (49), Journal of Managerial Psychology (46) and Personnel Review (46). Meanwhile, Frontiers in Psychology (38) and International Journal of Hospitality Management (35) published the lowest number of articles. As for the citation, the Journal of Applied Psychology published by APA recorded the highest number of citations (22365 citations) with a Cite Score of 12.3, SJR 2020 of 6.522, and SNIP 2020 of 4.185 compared to the other sources. Whereas, Frontiers in Psychology (333 citations) published by Frontiers Media S.A. scored the lowest citation (Cite Score=3.5, SJR 2020=0.947, and SNIP 2020=1.46).

Table 9. Top 10 most active source titles

\begin{tabular}{|c|c|c|c|c|c|c|}
\hline Source Title & TP & TC & Publisher & $\begin{array}{l}\text { Cite } \\
\text { Score }\end{array}$ & $\begin{array}{l}\text { SJR } \\
2020\end{array}$ & $\begin{array}{l}\text { SNIP } \\
2020\end{array}$ \\
\hline $\begin{array}{lr}\text { International Journal of } \\
\text { Human } & \text { Resource } \\
\text { Management } & \end{array}$ & 74 & 2684 & Taylor \& Francis & 6.9 & 1.378 & 1.842 \\
\hline $\begin{array}{l}\text { International Journal of } \\
\text { Environmental Research } \\
\text { and Public Health }\end{array}$ & 52 & 388 & $\begin{array}{l}\text { Frontiers Media } \\
\text { S.A. }\end{array}$ & 3.4 & 0.747 & 1.356 \\
\hline $\begin{array}{l}\text { Journal of Applied } \\
\text { Psychology }\end{array}$ & 49 & 22365 & $\begin{array}{l}\text { American } \\
\text { Psychological } \\
\text { Association (APA) }\end{array}$ & 12.3 & 6.522 & 4.185 \\
\hline $\begin{array}{l}\text { Journal of Managerial } \\
\text { Psychology }\end{array}$ & 46 & 3425 & Emerald & 3.1 & 0.878 & 1.069 \\
\hline Personnel Review & 46 & 924 & Emerald & 3.8 & 0.8 & 1.379 \\
\hline $\begin{array}{l}\text { Journal of Vocational } \\
\text { Behavior }\end{array}$ & 42 & 3856 & Elsevier & 8.4 & 2.607 & 2.8 \\
\hline
\end{tabular}




\begin{tabular}{|c|c|c|c|c|c|c|}
\hline $\begin{array}{l}\text { Journal of Nursing } \\
\text { Management }\end{array}$ & 40 & 1236 & Wiley-Blackwell & 3.3 & 0.925 & 1.42 \\
\hline \multicolumn{7}{|l|}{ Journal of Organizational } \\
\hline Behavior & 40 & 5558 & Wiley-Blackwell & 11.8 & 3.938 & 3.598 \\
\hline & & & Frontiers Media & & & \\
\hline Frontiers In Psychology & 38 & 333 & S.A. & 3.5 & 0.947 & 1.46 \\
\hline $\begin{array}{l}\text { International Journal of } \\
\text { Hospitality Management }\end{array}$ & 35 & 1672 & Elsevier & 9.4 & 2.321 & 2.876 \\
\hline
\end{tabular}

Notes: $\mathrm{TP}=$ total number of publications; $\mathrm{TC}=$ total citations.

- What is the status of the latest article citation metrics analysis?

Table 10, represents the number of metric citations analysed using Harzing's Publish or Perish software. Based on this analysis, 5527 articles were published and 174523 citations were recorded in the past 59 years. The average citation for each year was estimated at 2908.72. Meanwhile, the average citation for each article was 31.58, and the average citation for each author was 71890.84 . Whereas, articles that were related to organizational support estimated $164 \mathrm{~h}$-index and $314 \mathrm{~g}$-index.

Table 10. Citations metrics

\begin{tabular}{ll}
\hline Metrics & Data \\
\hline Publication years & $1962-2021$ \\
Citation years & $60(1962-2022)$ \\
Papers & 5527 \\
Citations & 174523 \\
Citations/year & 2908.72 \\
Citations/paper & 31.58 \\
Citations/author & 71890.84 \\
Papers/author & 2355.75 \\
h-index & 164 \\
g-index & 314 \\
\hline
\end{tabular}

- Which article is the most popular and has the highest citations?

The top 20 articles listed in Table 10 were those with the highest citations. The most popular article was also the highly cited article entitled "Perceived organizational support" authored by Eisenberger in 1986, with 4096 citations over 59 years and an average annual citation of 113.78 citations. In this paper, Eisenberger et al., (1986) revealed that employees' motivation to work is projected to increase perceived organisational support. Efforts to increase job performance, are reliant on the strength of social exchange ideas for material and non-material rewards. Succeeded by an article entitled "Perceived organizational support: A review of the literature" authored by Rhoades and Eisenberger in 2002 with 3118 citations. Rhoades and Eisenberger (2002) article summarised 70 studies on employee perceived organizational support using meta-analysis which included three categories of perceived organizational support namely fairness, supervisor support, and reward. Furthermore, Rhoades and Eisenberger (2002) study also explained that the perceived 
organizational support felt by employees was related to the satisfaction of employees working in a positive environment within an organization. Hence, employee trust in the organization believes that the organization has met employees' socioemotional needs and appreciation based on employees' discretion and sense of duty (Rhoades \& Eisenberger, 2002).

Table 10. Highly cited articles

\begin{tabular}{|c|c|c|c|c|c|}
\hline No. & Authors & Title & Year & Cites & $\begin{array}{l}\text { CitesPer } \\
\text { Year }\end{array}$ \\
\hline 1 & $\begin{array}{l}\text { R. Eisenberger, R. } \\
\text { Huntington, S. } \\
\text { Hutchison, D. Sowa }\end{array}$ & Perceived Organizational Support & 1986 & 4096 & 113.78 \\
\hline 2 & $\begin{array}{l}\text { L. Rhoades, R. } \\
\text { Eisenberger }\end{array}$ & $\begin{array}{l}\text { Perceived organizational support: A } \\
\text { review of the literature }\end{array}$ & 2002 & 3118 & 155.9 \\
\hline 3 & $\begin{array}{l}\text { V. Venkatesh, } \mathrm{H} . \\
\text { Bala }\end{array}$ & $\begin{array}{l}\text { Technology acceptance model } 3 \text { and } \\
\text { a research agenda on interventions }\end{array}$ & 2008 & 3013 & 215.21 \\
\hline 4 & A.M. Saks & $\begin{array}{l}\text { Antecedents and consequences of } \\
\text { employee engagement }\end{array}$ & 2006 & 1992 & 124.5 \\
\hline 5 & $\begin{array}{l}\text { S.J. Wayne, L.M. } \\
\text { Shore, R.C. Liden }\end{array}$ & $\begin{array}{l}\text { Perceived organizational support and } \\
\text { leader-member exchange: A social } \\
\text { exchange perspective }\end{array}$ & 1997 & 1913 & 76.52 \\
\hline 6 & $\begin{array}{ll}\text { B.L. Rich, J.A. } \\
\text { Lepine, } \\
\text { Crawford }\end{array}$ & $\begin{array}{l}\text { Job engagement: Antecedents and } \\
\text { effects on job performance }\end{array}$ & 2010 & 1602 & 133.5 \\
\hline 7 & $\begin{array}{l}\text { R. Eisenberger, P. } \\
\text { Fasolo, V. Davis- } \\
\text { LaMastro }\end{array}$ & 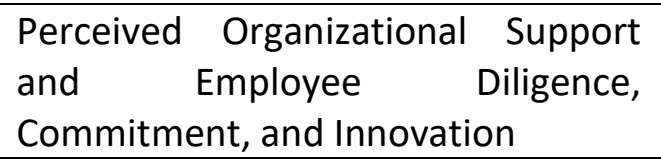 & 1990 & 1509 & 47.16 \\
\hline 8 & $\begin{array}{l}\text { R. Eisenberger, S. } \\
\text { Armeli, } \quad \text { B. } \\
\text { Rexwinkel, P.D. } \\
\text { Lynch, L. Rhoades } \\
\end{array}$ & $\begin{array}{l}\text { Reciprocation of perceived } \\
\text { organizational support }\end{array}$ & 2001 & 1378 & 65.62 \\
\hline 9 & J. Zhou, J.M. George & $\begin{array}{l}\text { When job dissatisfaction leads to } \\
\text { creativity: Encouraging the } \\
\text { expression of voice }\end{array}$ & 2001 & 1295 & 61.67 \\
\hline 10 & $\begin{array}{l}\text { R. Eisenberger, F. } \\
\text { Stinglhamber, C. } \\
\text { Vandenberghe, I.L. } \\
\text { Sucharski, } \\
\text { Rhoades }\end{array}$ & $\begin{array}{l}\text { Perceived supervisor support: } \\
\text { Contributions to perceived } \\
\text { organizational support and } \\
\text { employee retention }\end{array}$ & 2002 & 1214 & 60.7 \\
\hline 11 & $\begin{array}{l}\text { R.P. Settoon, N. } \\
\text { Bennett, R.C. Liden }\end{array}$ & $\begin{array}{l}\text { Social exchange in organizations: } \\
\text { Perceived organizational support, } \\
\text { leader-member exchange, and } \\
\text { employee reciprocity }\end{array}$ & 1996 & 1121 & 43.12 \\
\hline 12 & T.M. Amabile & How to kill creativity. & 1998 & 1117 & 46.54 \\
\hline
\end{tabular}




\begin{tabular}{|c|c|c|c|c|c|}
\hline 13 & P. Cooke & $\begin{array}{l}\text { Regional innovation systems, } \\
\text { clusters, and the knowledge } \\
\text { economy }\end{array}$ & 2001 & 1098 & 52.29 \\
\hline 14 & $\begin{array}{ll}\text { L. Rhoades, } & \text { R. } \\
\text { Eisenberger, } & \text { S. } \\
\text { Armeli } & \\
\end{array}$ & $\begin{array}{l}\text { Affective commitment to the } \\
\text { organization: The contribution of } \\
\text { perceived organizational support }\end{array}$ & 2001 & 1080 & 51.43 \\
\hline 15 & $\begin{array}{l}\text { C.A. Thompson, L.L. } \\
\text { Beauvais, } \\
\text { Lyness }\end{array}$ & $\begin{array}{l}\text { When Work-Family Benefits Are Not } \\
\text { Enough: The Influence of Work- } \\
\text { Family Culture on Benefit Utilization, } \\
\text { Organizational Attachment, and } \\
\text { Work-Family Conflict }\end{array}$ & 1999 & 1021 & 44.39 \\
\hline 16 & $\begin{array}{l}\text { D.G. Allen, L.M. } \\
\text { Shore, R.W. Griffeth }\end{array}$ & $\begin{array}{l}\text { The role of perceived organizational } \\
\text { support and supportive human } \\
\text { resource practices in the turnover } \\
\text { process }\end{array}$ & 2003 & 877 & 46.16 \\
\hline 17 & $\begin{array}{ll}\text { R. Eisenberger, } & \text { J. } \\
\text { Cummings, } & \mathrm{S} . \\
\text { Armeli, P. Lynch } & \\
\end{array}$ & $\begin{array}{l}\text { Perceived organizational support, } \\
\text { discretionary treatment, and job } \\
\text { satisfaction }\end{array}$ & 1997 & 816 & 32.64 \\
\hline 18 & $\begin{array}{l}\text { L.M. Shore, S.J. } \\
\text { Wayne }\end{array}$ & $\begin{array}{l}\text { Commitment and } \text { Employee } \\
\text { Behavior: Comparison of Affective } \\
\text { Commitment and Continuance } \\
\text { Commitment With Perceived } \\
\text { Organizational Support }\end{array}$ & 1993 & 698 & 24.07 \\
\hline 19 & $\begin{array}{l}\text { F. Yuan, } \\
\text { Woodman }\end{array}$ & $\begin{array}{l}\text { Innovative behavior in the } \\
\text { workplace: The role of performance } \\
\text { and image outcome expectations }\end{array}$ & 2010 & 697 & 58.08 \\
\hline 20 & E.M. Whitener & $\begin{array}{l}\text { Do "high commitment" human } \\
\text { resource practices affect employee } \\
\text { commitment?: A cross-level analysis } \\
\text { using hierarchical linear modeling }\end{array}$ & 2001 & 657 & 31.29 \\
\hline
\end{tabular}

- What are the most popular author keywords in publishing organizational support articles?

Table 11 and Figure 4 indicated the presence of 5 colour clusters, namely red, green, blue, yellow, and purple. The total number of keywords in all clusters was 30 . The red cluster had 12 keywords, with the most frequently used keyword being "Organizational support" (493) and a TLS of 339. The green cluster had 9 keywords, with the most commonly used keyword being "Perceived organizational support" (924) and a TLS of 806. "Perceived organizational support" was the most frequently used keyword compared to others in all five clusters. Meanwhile, the blue cluster also contained 4 keywords, with "Turnover Intention" (148) being the most frequently used keyword with a TLS of 252.

The yellow cluster was comprised of three keywords. "Work Engagement" (82) was often used in this cluster with a TLS of 109. Whereas, the purple cluster had two keywords "Job Satisfaction" (267) was the keyword with the highest TLS of 344). The top five most popular keywords in the organizational support articles were "Organizational support", "Perceived organizational support", "Turnover Intention", "Work engagement", and "Job 
Satisfaction". These five keywords represented the theme of each coloured cluster as illustrated in the Vosviewer visualisation (Figure 4) and listed in Table 11. Based on these keywords, the red cluster with 12 keywords had a strong relationship with nursing jobs as it is often associated with stress, burnout, work-family conflict, Well-Being, leadership, social support and Covid -19. Furthermore, the workload in this profession is extremely high where it could affect the mental and emotional well-being of the nursing staff as it also requires more energy and working hours based on the work schedule.

The current COVID-19 pandemic has made the lives of the frontliners even more challenging with an increased burden. Also, the green cluster indicated that the study of Perceived Organizational Support used social exchange theory stipulating a relationship with commitment, organizational citizenship behaviour, organizational justice, performance, organizational identification, leader-member exchange and trust. Meanwhile, the blue cluster indicated a relationship between turnover intention with affective commitment and employee engagement. The yellow cluster indicated a relationship between work engagement with job performance and supervisor support. Finally, based on the purple cluster, job satisfaction exhibited a relationship with organizational commitment.

Table 11. Top 30 author keywords based on the frequency with the strength of the relationship between 5 clusters

\begin{tabular}{llll}
\hline Item & Author keywords & Occurrences & $\begin{array}{l}\text { Total } \\
\text { (TLS) }\end{array}$ \\
\hline & Cluster Red - Organizational Support & Strength \\
\hline 1 & Burnout & 98 & 100 \\
2 & Covid-19 & 43 & 44 \\
3 & Leadership & 72 & 51 \\
4 & Mental Health & 54 & 27 \\
5 & Nurses & 80 & 74 \\
6 & Nursing & 68 & 39 \\
7 & Organizational Support & 493 & 339 \\
8 & Qualitative Research & 60 & 20 \\
9 & Social Support & 65 & 64 \\
10 & Stress & 57 & 60 \\
11 & Well-Being & 44 & 52 \\
12 & Work-Family Conflict & 48 & 52 \\
\hline \multicolumn{5}{l}{} & Cluster Green - Perceived Organizational Support & \\
\hline 1 & Commitment & 38 & 56 \\
2 & Leader-Member Exchange & 47 & 77 \\
3 & Organizational Citizenship Behaviour & 107 & 176 \\
4 & Organizational Identification & 44 & 63 \\
5 & Organizational Justice & 45 & 68 \\
6 & Perceived Organizational Support & 924 & 806 \\
7 & Performance & 41 & 41 \\
8 & Social Exchange Theory & 108 & 153 \\
9 & Trust & 43 & 53 \\
\hline 1 & Cluster Blue - Turnover Intention & & \\
2 & Affective Commitment & 74 & 66 \\
& Employee Engagement & 44 &
\end{tabular}




\begin{tabular}{llll}
3 & India & 35 & 43 \\
4 & Turnover Intention & 148 & 252 \\
\hline & Cluster Yellow - Work Engagement & & \\
\hline 1 & Job Performance & 60 & 91 \\
2 & Supervisor Support & 44 & 61 \\
3 & Work Engagement & 82 & 109 \\
\hline & Cluster Purple - Job Satisfaction & & \\
\hline 1 & Job Satisfaction & 267 & 344 \\
2 & Organizational Commitment & 160 & 245 \\
\hline
\end{tabular}

\& Vosviewer

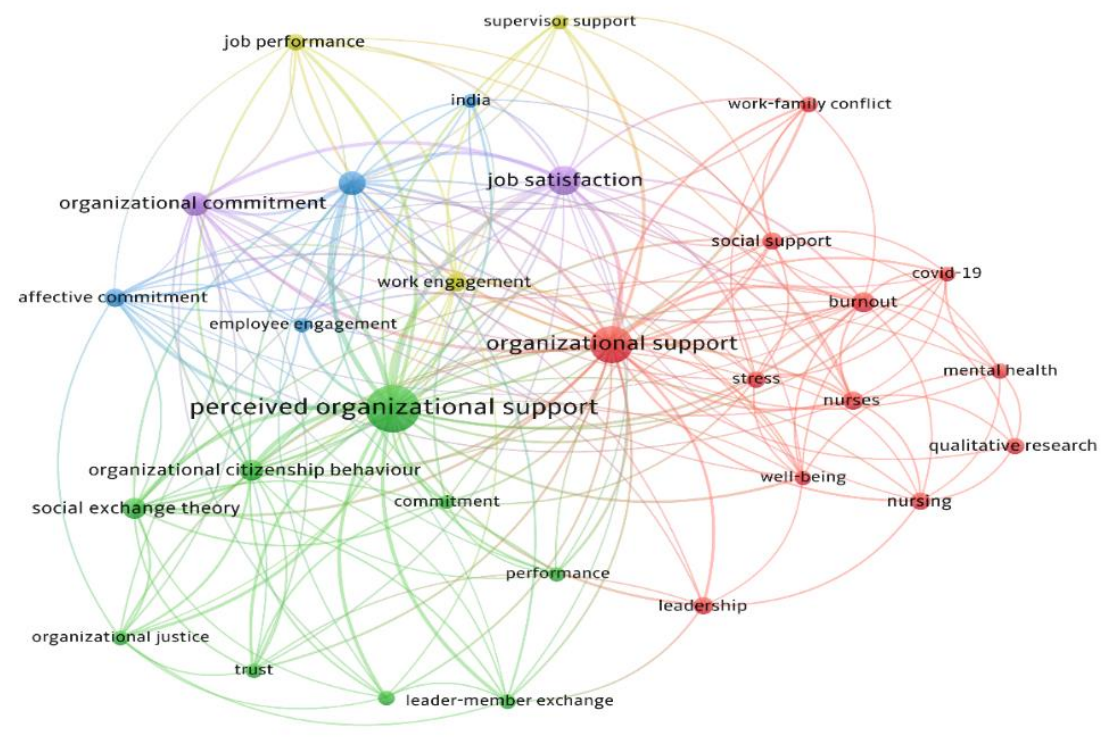

Figure 4. Network visualisation map of the author keywords

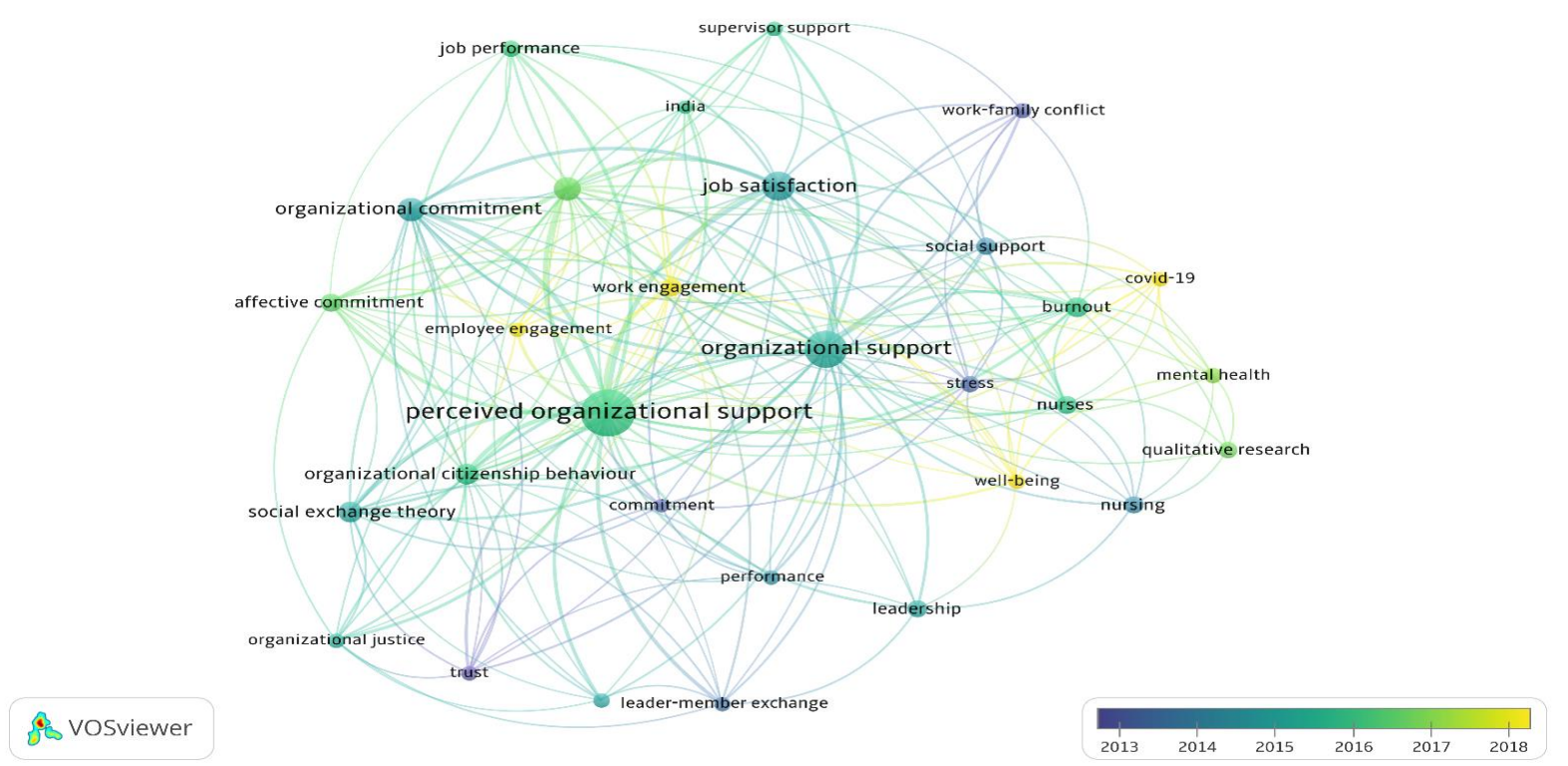

Figure 5. Overlay visualisation map of the author keywords 
Figure 5 shows the overlay visualization map of the author keywords. The dark blue keywords are among the earliest research topics conducted in organizational support based on the overlay visualization. The earliest research keywords have focused on trust, social exchange theory, commitment, stress, social support, leader-member exchange, job satisfaction, workfamily conflict, organizational support, nursing, leadership and organizational commitment.

While the light green keywords between the years 2014 to 2016 are perceived organizational support, supervisor support, organizational citizenship behaviour, burnout, nurses, turnover intention and organizational justice. On the other hand, the keywords light green to yellow between 2017 and above are the latest research keywords conducted on organizational support topics such as Covid-19, well-being, mental health, work engagement, employee engagement, affective commitment and qualitative research.

\section{Conclusion}

In conclusion, this study explored the development or trends of organizational support studies in the past 59 years. This bibliometric analysis provided comprehensive information from extant studies on articles related to organizational support. A total of 11 research questions that were constructed were answered based on research findings. This study also outlined the types of documents and sources in article publishing, languages used, fields, publishing trends, countries with highest publications, most influential institutions, most productive authors, most active sources in publishing the study article, metric analysis status, popular articles, and the most popular author keywords. All the information were obtained from a collection of publication extracted from the Scopus database. The information retrieved could guide future researchers and organizational policymakers to strengthen and add more knowledge in this field.

One of the limitations of this study was that the articles were only retrieved from the Scopus database. Hence, future studies could incorporate other databases such as Web of Sciences, Google scholar, Dimension, etc. In addition, researchers could also compare the findings from different databases in the future. On the other hand, this study only focused on documents and sources of publication of journal articles. Therefore, future studies could include various documents and other sources such as books, reviews, notes, etc. Also, the study of organizational support can be extended by linking other variables such as performance appraisal fairness. Future studies can also be extended to other government employment sectors such as police, immigration, and customs.

Studies on organizational support are mainly conducted in western countries. The literature also clearly stated that organizational support is effective in western countries because it adopted individualistic culture compared to Asian countries which adopt a rather collectivistic culture (Rockstuhl et al., 2020). Based on the number of publications, western countries published the most articles on organizational support compared to Asian countries. However, according to Eisenberger et al. (2020), organizational support theory appeared to be more effective in countries that practice a collectivist culture, contrary to the findings of Rockstuhl et al. (2020). Therefore, it is recommended that the study of organizational support could be multiplied in Asian countries to assess the impacts of organizational support in countries that practice collectivist culture. The information obtained from this study contributes to the body of knowledge which can be utilised by organizations, organizational policymakers, and researchers to identify future research gaps. 


\section{Acknowledgement}

The authors declare no conflict of interest.

\section{Corresponding Author}

Brenda Ranee Francis

Faculty of Cognitive Sciences and Human Development, University Malaysia Sarawak, 94300 Kota Samarahan, Sarawak, Malaysia

Email: brenda14956@yahoo.com

\section{References}

Ahmi, A., \& Mohamad, R. (2019). Bibliometric analysis of global scientific literature on web accessibility. International Journal of Recent Technology and Engineering, 7(6), 250258.

Aldamman, K., Tamrakar, T., Dinesen, C., Wiedemann, N., Murphy, J., Hansen, M., Elsiddig Badr, E., Reid, T., \& Vallières, F. (2019). Caring for the mental health of humanitarian volunteers in traumatic contexts: the importance of organisational support. European Journal of Psychotraumatology, 10(1). https://doi.org/10.1080/20008198.2019.1694811

Andoh, S. S., Ghansah, B., Okogun-Odompley, J. N., \& Benuwa, B.-B. (2021). The Effect of Job Satisfaction on Turnover Intentions: The Mediating Role of Organizational Commitment. International Journal of Risk and Contingency Management, 10(1), 20-35. https://doi.org/10.4018/IJRCM.2021010103

Arnéguy, E., Ohana, M., \& Stinglhamber, F. (2018). Organizational justice and readiness for change: A concomitant examination of the mediating role of perceived organizational support and identification. Frontiers in Psychology, 9(JUL), 1-13. https://doi.org/10.3389/fpsyg.2018.01172

Arnéguy, E., Ohana, M., \& Stinglhamber, F. (2020). Overall justice, perceived organizational support and readiness for change: the moderating role of perceived organizational competence. Journal of Organizational Change Management, 33(5), 765-777. https://doi.org/10.1108/JOCM-12-2019-0373

Aselage, J., \& Eisenberger, R. (2003). Perceived organizational support and psychological contracts: A theoretical integration. Journal of Organizational Behavior, 24(SPEC. ISS.), 491-509. https://doi.org/10.1002/job.211

Baran, B. E., Shanock, L. R., \& Miller, L. R. (2012). Advancing Organizational Support Theory into the Twenty-First Century World of Work. Journal of Business and Psychology, 27(2), 123-147. https://doi.org/10.1007/s10869-011-9236-3

Burnham, J. F. (2006). Scopus database: A review. Biomedical Digital Libraries, 3, 1-8. https://doi.org/10.1186/1742-5581-3-1

Caesens, G., Marique, G., Hanin, D., \& Stinglhamber, F. (2016). The relationship between perceived organizational support and proactive behaviour directed towards the organization. European Journal of Work and Organizational Psychology, 25(3), 398-411. https://doi.org/10.1080/1359432X.2015.1092960

Caesens, G., Stinglhamber, F., Demoulin, S., De Wilde, M., \& Mierop, A. (2019). Perceived organizational support and workplace conflict: The mediating role of failure-related trust. Frontiers in Psychology, 9(JAN), 1-13. https://doi.org/10.3389/fpsyg.2018.02704

Côté, K., Lauzier, M., \& Stinglhamber, F. (2021). The relationship between presenteeism and job satisfaction: A mediated moderation model using work engagement and perceived 
organizational support. European Management Journal, 39(2), 270-278. https://doi.org/10.1016/j.emj.2020.09.001

Eisenberger, R., Armeli, S., Rexwinkel, B., Lynch, P. D., \& Rhoades, L. (2001). Reciprocation of perceived organizational support. Journal of Applied Psychology, 86(1), 42-51. https://doi.org/10.1037/0021-9010.86.1.42

Eisenberger, R., Huntington, R., Hutchison, S., \& Sowa, D. (1986). Perceived Organizational Support. Journal of Applied Psychology, 71(3), 500-507.

Eisenberger, R., Rhoades Shanock, L., \& Wen, X. (2020). Perceived Organizational Support: Why Caring about Employees Counts. Annual Review of Organizational Psychology and Organizational Behavior, 7, 101-124. https://doi.org/10.1146/annurev-orgpsych012119-044917

Ekmekcioglu, E. B., \& Aydogan, E. (2019). A moderated mediation model of the relationship between organizational justice and turnover intention. International Journal of Organizational Analysis, 27(4), 1073-1092. https://doi.org/10.1108/IJOA-06-2018-1448

Fazio, J., Gong, B., Sims, R., Yurova, Y., Fazio, J., Gong, B., Sims, R., \& Yurova, Y. (2017). "The role of affective commitment in the relationship between social support and turnover intention." 55(3), 512-525. https://doi.org/org/10.1108/LODJ-05-2014-0090</a>

Gordon, S., Tang, C. H. (Hugo), Day, J., \& Adler, H. (2019). Supervisor support and turnover in hotels: Does subjective well-being mediate the relationship? International Journal of Contemporary Hospitality Management, 31(1), 496-512.

https://doi.org/10.1108/IJCHM-10-2016-0565

Hoak, G. (2021). Covering COVID: Journalists' Stress and Perceived Organizational Support While Reporting on the Pandemic. Journalism \& Mass Communication Quarterly, 1-21. https://doi.org/10.1177/10776990211015105

Kim, K. Y., Eisenberger, R., \& Baik, K. (2016). Perceived organizational support and affective organizational commitment: Moderating influence of perceived organizational competence. Journal of Marriage and Family, 37, 558-583. https://doi.org/10.1002/job

Kurtessis, J. N., Eisenberger, R., Ford, M. T., Buffardi, L. C., Stewart, K. A., \& Adis, C. S. (2017a). Perceived Organizational Support: A Meta-Analytic Evaluation of Organizational Support Theory. Journal of Management, 43(6), 1854-1884.

https://doi.org/10.1177/0149206315575554

Kurtessis, J. N., Eisenberger, R., Ford, M. T., Buffardi, L. C., Stewart, K. A., \& Adis, C. S. (2017b). Perceived Organizational Support: A Meta-Analytic Evaluation of Organizational Support Theory. Journal of Management, 43(6), 1854-1884.

https://doi.org/10.1177/0149206315575554

Moher, D., Liberati, A., Tetzlaff, J., Altman, D. G., Altman, D., Antes, G., Atkins, D., Barbour, V., Barrowman, N., Berlin, J. A., Clark, J., Clarke, M., Cook, D., D’Amico, R., Deeks, J. J., Devereaux, P. J., Dickersin, K., Egger, M., Ernst, E., ... Tugwell, P. (2009). Preferred reporting items for systematic reviews and meta-analyses: The PRISMA statement. PLoS Medicine, 6(7). https://doi.org/10.1371/journal.pmed.1000097

Nazir, S., Shafi, A., Atif, M. M., Qun, W., \& Abdullah, S. M. (2019). How organization justice and perceived organizational support facilitate employees' innovative behavior at work. Employee Relations: The International Journal, 41(6), 1288-1311. https://doi.org/10.1108/er-01-2017-0007

Nguyen, V. Q., Taylor, G. S., \& Bergiel, E. (2017). Organizational antecedents of job embeddedness. Management Research Review, 40(11), 1216-1235.

https://doi.org/10.1108/MRR-11-2016-0255 
Pritchard, A. (1969). "Statistical bibliography or bibliometrics." In J.Doc (Vol. 25, Issue 4).

Rhoades, L., \& Eisenberger, R. (2002). Perceived organizational support: A review of the literature. Journal of Applied Psychology, 87(4), 698-714. https://doi.org/10.1037/00219010.87.4.698

Rhoades, L., Eisenberger, R., \& Armeli, S. (2001). Affective commitment to the organization: The contribution of perceived organizational support. Journal of Applied Psychology, 86(5), 825-836. https://doi.org/10.1037/0021-9010.86.5.825

Rockstuhl, T., Eisenberger, R., Shore, L. M., Kurtessis, J. N., Ford, M. T., Buffardi, L. C., \& Mesdaghinia, S. (2020). Perceived organizational support (POS) across 54 nations: A cross-cultural meta-analysis of POS effects. Journal of International Business Studies, 51(6), 933-962. https://doi.org/10.1057/s41267-020-00311-3

Shore \& Wayne. (1993). Commitment and Employee Behavior: Comparison of Affective Commitment and Continuance Commitment With Perceived Organizational. Journal of Applied Psychology, 78(5), 774-780. https://doi.org/10.3969/j.issn.10019731.2017.01.007

Van Eck, N. J., \& Waltman, L. (2020). Manual for VOSviewer version 1.6.15. In Universiti Leiden: Vol. 4956 LNCS (Issue April). CWTS, Meaningful metrics. https://doi.org/10.1007/978-3-540-78646-7_21

Wong, D. (2018). VOSviewer. Technical Services Quarterly, 35(2), 219-220. https://doi.org/10.1080/07317131.2018.1425352

Zakaria, R., Ahmi, A., Ahmad, A. H., \& Othman, Z. (2021). Worldwide melatonin research: a bibliometric analysis of the published literature between 2015 and 2019. Chronobiology International, 38(1), 27-37. https://doi.org/10.1080/07420528.2020.1838534

Zeffane, R., \& Bani Melhem, S. J. (2017). Trust, job satisfaction, perceived organizational performance and turnover intention: A public-private sector comparison in the United Arab Emirates. Employee Relations, 39(7), 1148-1167. https://doi.org/10.1108/ER-062017-0135 